\title{
ballot
}

\section{O sistema de cotas eleitorais na Espanha: uma análise da Ley de Igualdad (LO 3/2007)}

Claudia Pilatti Tavarnaro (UFPR, Brasil)

claudiaptavarnaro@gmail.com

Universidade Federal do Paraná

Praça Santos Andrade, 50 - Centro

Curitiba/PR - Brasil - 80020-300 


\title{
Resumo
}

Com o objetivo de estudar a eficácia das cotas eleitorais à presença feminina nos postos de decisão política, o presente artigo debruça-se sobre a experiência espanhola com o sistema de cotas eleitorais vigente. Primeiramente, dados estatísticos são expostos como demonstrativo do contexto sociocultural e político atual da Espanha. Em especial, os dados sobre a educação e a renda entre os diversos setores da população, incluindo os comparativos em relação ao sexo, são apresentados como avaliativos da igualdade entre gêneros. A partir do levantamento de dados empíricos, é analisado o sistema eleitoral espanhol, em relação à eficácia de suas cotas eleitorais e em relação à eficácia da "Ley de Igualdad", que, em 2007, tornou de observância obrigatória, a todos os partidos, o respeito às cotas eleitorais nas listas de candidatos apresentadas às eleições. Por fim, são tecidas algumas críticas ao sistema de cotas eleitorais, com o esclarecimento de suas insuficiências práticas no que tange à garantia da igualdade de oportunidade à participação política entre os gêneros.

Palavras-chave: direito eleitoral; sistema de cotas; Espanha.

\begin{abstract}
The object of this paper is the study of the electoral quotas effectiveness to women's presence in political and decision-making positions. The study focuses on Spanish experience with current electoral quota system. In the first place, the study demonstrates, with statistical data, the present social, cultural and political Spanish environment. Particularly, education and income data among social sectors, including comparative gender data, are presented as indicators of gender equality in Spain. The empirical data points to the final effectiviness of electoral quotas and the final effectiviness of the "Ley de Igualdad", which, in 2007, turned the observance of electoral quotas, on candidates lists submitted for election, mandatory for all political parties. Finally, electoral quota system is criticized, as the study points pratical difficulties in terms of ensuring the equality of opportunity in political participation between genders.
\end{abstract}

Keywords: Election Law; women quotas; Spain. 


\section{Breve apresentação de dados socioculturais}

Segundo o Instituto Nacional de Estadística (INE), responsável pelo censo demográfico espanhol, a população espanhola total, em 2014, era de 46.464.053, habitantes, sendo 22.843 .719 homens e 23.620.334 mulheres ${ }^{1}$. O índice de GINI, referência para medir a desigualdade social nos países, em 2013, correspondia a 32,870, segundo dados Banco Mundial.

A expectativa de vida ao nascer corresponde a uma média de 82 anos. O Produto Interno Bruto (PIB) correspondia, em 2013, a 1,393 trilhão de dólares, sendo a renda média para cada casa espanhola correspondente a 26.775 euros anuais. Do total do PIB, o governo destinava, em 2011, 5\% do montante aos gastos com educação, segundo os dados oficiais, $97,2 \%$ dos espanhóis são alfabetizados. Entre as mulheres de 15 a 24 anos, o índice de alfabetização é de $99,7 \%$, sendo de $99,6 \%$ entre os homens na mesma faixa etária ${ }^{2}$. Para o ano de 2014, a Espanha aparecia na 29a posição do ranking mundial estabelecido pelo Global Gender Gap Report, que mede a igualdade entre os gêneros em mais de 100 países³.

\section{A Constituição Espanhola: o princípio da igualdade e o direito ao voto}

A Constituição vigente na Espanha data de 1978, momento de redemocratização e de fim do governo ditatorial de Francisco Franco, com a consequente desconcentração do poder político. Conforme a disposição constitucional, o país está dividido em 17 comunidades autônomas e duas cidades autônomas (Ceuta e Melilla). Apesar de ser formalmente um Estado unitário, funcionalmente, pode-se dizer que o Estado espanhol atua como federação de comunidades autônomas, com a atribuição de diferentes níveis de autonomia, principalmente, em relação ao sistema educacional, de saúde e orçamentário4.

A igualdade é princípio consagrado pela Constituição espanhola em dispositivos diversos, a exemplo dos artigos 1.1, 9.2 e 149.1.1. Além de consagrado pela Constituição, o princípio aparece em diversos compromissos internacionais firmados pela Espanha, a exemplo da Declaração Universal de Direitos Humanos, de 1948, do Convênio Europeu para a Proteção dos Direitos Humanos e Liberdades Públicas (1950), do Pacto Internacional de Direitos Civis e Políticos (1966) e da Carta de Direitos Fundamentais da União Europeia (2000), apenas para citar alguns.

O direito ao voto foi reconhecido às mulheres, na Espanha, em 1931, quando, no dia 8 de março, o Decreto do governo provisório, firmado por Miguel Maura, que normalizou as

\footnotetext{
1. Dados fornecidos pelo INE (Instituto Nacional de Estadística), ver: INE, Base. Demografía y población. Disponível em: http://www.ine.es/inebmenu/mnu_cifraspob.htm/. Acesso em: 18 mar. 2015.

2. Dados fornecidos pelo Banco Mundial, ver: WORLD BANK. Data by countryः Spain. Disponível em: http://data.worldbank.org/country/spain. Acesso em: 18 mar. 2015.

3. Dados fornecidos pelo Fórum Econômico Mundial, ver: WORLD FORUM ECONOMICS. Global Gender Gap Report. Disponível em: http://reports.weforum.org/global-gender-gap-report-2014/ economies/\#economy=ESP. Acesso em: 20 set. 2015.

4. AGENCIA ESTATAL BOLETÍN OFICIAL DEL ESTADO (BOE). La Constitución Española. Disponível em: https://www.boe.es/legislacion/constitucion.php/. Acesso em: 10 set. 2015.
} 
eleições para a Assembleia Constituinte, à época, declarou as mulheres elegíveis. Entre os 470 deputados eleitos naquele ano, apenas duas eram mulheres, Clara Campoamor, pelo Partido Radical de Lerroux, e Victoria Kent, pelo Partido Radical Socialista, ambas eleitas em Madri 5 .

Clara Campoamor venceu a votação parlamentar pela inclusão do art. 34 do projeto de emenda constitucional, que, posteriormente, foi incorporado à Constituição de 1937 como art. 36. O artigo dispunha o seguinte: "Los ciudadanos de uno y otro sexo, mayores de 23 años, tendrán los mismos derechos electorales, conforme determinem las leyes". A votação foi vencida por 161 votos contra 121 e, somente após, as mulheres foram reconhecidas como cidadãs de pleno direito ${ }^{6}$.

Já durante a Ditadura de Francisco Franco (1939-1975), houve grande retrocesso na garantia da igualdade e dos direitos das mulheres. Organizações preocupadas com os direitos femininos precisaram manter-se na clandestinidade, durante aquele período. Em 1976, com o fim da Ditadura, esses movimentos revestiram-se de legitimidade. Em 1977, dos 248 candidatos eleitos para o Senado, apenas seis eram mulheres (2,4\%). Segundo Gallego ${ }^{7}$, apesar do resultado modesto, essa primeira eleição de mulheres para cargos políticos representou grande importância para a expressão pública e também através dos meios de comunicação dos interesses das mulheres espanholas.

\section{Sistema político espanhol}

Oficialmente constituída como Reino da Espanha, a nação espanhola é uma monarquia parlamentar constitucional. Atualmente, o posto de Chefe de Estado é ocupado pelo Rei Filipe VI, enquanto o posto de Chefe de Governo é ocupado pelo primeiro ministro Mariano Rajoy+ $\mathrm{O}$ Parlamento é bicameral, composto pelas Cortes Generales, órgãos supremos do Poder Legislativo, que compreendem o Senado e a Câmara dos Deputados ${ }^{8}$.

A formação bicameral do Parlamento foi retomada, após a ditadura franquista, com a "Ley para la reforma política", de 1977. Após a edição da Lei e da eleição da primeira Legislatura democrática, começou a ser debatida uma nova constituição. Em 27 de dezembro de 1978, foi aprovado um novo diploma constitucional, mediante um referendo, convocado em 6 de dezembro de 1978, para o qual houve aprovação maciça da população?.

Pela disposição da Constituição espanhola (CE), cada uma das Cortes Generales tem autonomia para aprovar seu Regulamento interno e seu orçamento. Além disso, cada uma das

5. OTALORA, Ainhoa Uribe. Las cuotas de género y su aplicación em Espanã: los effectos de la Ley de Igualdad (LO 3/2007) em las Cortes Generales y los Parlamentos Autonómicos. Madrid: Revista de Estudios Políticos, n 160, p. 159-197, abr. 2013, p. 163.

6. VALCÁRCEL, Amelia. El debate sobre el voto femenino en la Constitución de 1931. Madrid: Congreso de los Diputados, 2002.

7. GALLEGO MÉNDEZ, María Teresa. Women’s Political Engagement in Spain. New York: Yale University Press, 1994, p. 660-673.

8. ESPAÑA. Constitución Española, art. 68.1.

9. CASTRILLÓN, Gonzalo Anes y Álvarez. Veinticinco años de la Constitución Española. Madrid: Real Academia de la Historia, 2006, p. 54. 
Casas legislativas elege o Presidente e os membros componentes de uma Mesa diretora. Há comissões próprias, formadas de forma exclusiva, pelas Casas, assim como comissões mistas, formadas por membros de ambas (art. 72, CE).

Assim como no Brasil, na Espanha, não pode o congressista ser membro das duas Cortes ao mesmo tempo (art. 67.1, CE). As principais funções desempenhadas pelo Legislativo espanhol podem ser distintas em: (i) legislativa (aprovação de leis); (ii) "presupuestaria" (aprovação do orçamento anual do Estado); (iii) autorização de tratados internacionais; (iv) controle da ação do governo; (v) integração territorial (vi) eleição e composição de outros órgãos ${ }^{10}$.

\section{Sistema eleitoral espanhol}

Sobre o direito ao sufrágio, a Lei Orgânica no 5 de 1985, que regulou o sistema eleitoral espanhol, determina um critério objetivo: podem votar aqueles que atingem a maioridade, aos 18 anos. No entanto, são impedidos de votar os maiores de 18 anos que forem expressamente declarados incapazes ao voto, por sentença judicial transitada em julgado; os condenados judicialmente com a pena principal ou acessória de privação do direito ao voto; os internados em hospital psiquiátrico, durante a sua internação, sempre que a sentença judicial assim determinar ${ }^{11}$.

Sobre a elegibilidade, a referida Lei dispóe que, como regra, aqueles que podem votar tornam-se elegíveis. Há, contudo, diversas hipóteses de inelegibilidade trazidas pela legislação. Por exemplo, são inelegíveis os membros da Família Real e seus cônjuges; os Presidentes do Tribunal Constitucional, do Tribunal Supremo, do Conselho de Estado, do Tribunal de Contas; os Presidentes e Secretários das Juntas Eleitorais; os condenados à pena restritiva de liberdade, enquanto ela perdurar; apenas para citar algumas das hipóteses. ${ }^{12}$

O sistema eleitoral é organizado distritalmente. O distrito eleitoral é a província. No total, há 50 províncias espanholas. Os votos são direcionados aos partidos, responsáveis por predefinir listas provinciais, com os seus respectivos candidatos. Os integrantes das listas são eleitos à medida que o partido político ao qual pertencem recebe votos (art. 68.2, CE).

Cabe a cada Junta Eleitoral regulamentar e fiscalizar a formação das listas eleitorais, pelos partidos políticos (art. 70, CE). Para estudar o sistema eleitoral espanhol, torna-se necessária a distinção entre o sistema adotado para a eleição de senadores e o sistema adotado para a eleição dos deputados.

Segundo a Lei Orgânica no 5 de 1985, o Congresso (Câmara dos Deputados) é composto por 350 deputados ${ }^{13}$. Ceuta e Melilla, as cidades autônomas espanholas, elegem, cada uma, um deputado, e as demais províncias, inicialmente, elegem no mínimo dois deputados, totalizando 102 deputados. As 248 cadeiras remanescentes são distribuídas igualmente entre as Províncias em relação proporcional às suas populações (art. 68.2, CE).

10. SENADO DE ESPAÑA. Funciones del Senado. Disponível em: http://www.senado.es/web/ conocersenado/temasclave/funcionessenado/index.html. Acesso em: 15 ago. 2015.

11. ESPAÑA. Ley Orgánica 5/1985, de 19 de Junio, art. 2 e 3.

12. ESPANA. Ley Orgánica 5/1985, de 19 de Junio, art. 6.

13. Ibid., art. 162 . 
O Senado, por sua vez, foi definido, no artigo 69.1 da Constituição espanhola, como Câmara de representação territorial e conta com 266 membros. Ceuta e Melilla elegem, cada uma, dois senadores (art. 69.2, CE). Para cada província, devem ser eleitos quatro senadores. Há uma divisão expressa do número de senadores para cada comunidade insular ou cada grupo de ilhas. Para as ilhas consideradas "maiores" (Gran Canaria, Mallorca e Tenerife), são eleitos três senadores, enquanto para os grupos de ilhas considerados "menores" (Ibiza-Fomentera, Menorca, Fuerteventura, Hierro, Lanzarote e La Palma), é eleito um senador (art. 69.3, CE).

As comunidades autônomas devem nomear um senador, no mínimo, e, para cada milhão de habitantes, nomear mais um senador (art. 69.4 e art. 69.5, CE). Dessa forma, dentro das províncias, os eleitores podem votar em três candidatos ao Senado, sendo dois suplentes. Ao final, os quatro candidatos mais votados serão eleitos (art. 69.1, art. 69.2, art. 69.4, art. 69.5, $\mathrm{CE}$ ). Os mandatos para as duas casas equivalem ao período de quatro anos (art. $68.4 \mathrm{e}$ art. $69.6, \mathrm{CE})$.

\section{5. "Ley de Igualdad" e a desigualdade de gênero}

No dia 22 de março de 2007, foi adotada a Ley de Igualdad ou Ley Orgánica 3/2007, que se destinou a criar mecanismos de ação positiva para a redução da desigualdade de gênero, não apenas nos cargos políticos, mas em âmbitos diversos da vida em sociedade, incluindo aqueles de tradicional predominância da livre iniciativa, como as empresas.

A Ley de Igualdad criou políticas públicas ativas de promoção da presença equitativa de mulheres em todos os setores sociais, com abrangência nacional e local. Para Teresa García Hernánde $z^{14}$, em primeiro lugar, a Lei 3/2007 determinou a adoção dos denominados planos obrigatórios de igualdade nas empresas; em segundo lugar, do fortalecimento de instrumentos que possibilitam a conciliação da vida familiar e do trabalho para as mulheres, com a ampliação de direitos femininos; em terceiro lugar, com o estabelecimento de cláusulas para a contratação administrativa; e, por fim, com a preocupação pela presença equilibrada de mulheres e homens nos pleitos eleitorais.

No que se refere ao sistema eleitoral, a Ley de Igualdad introduziu alteração no art. 44 bis da Ley Orgánica de Régimen Electoral General (LOREG) ou Lei Orgânica 5/1985, de 19 de julho. Sobre o seu principal objetivo, a Lei assim dispóe:

“(...) la Ley establece princípios de actuación de los Poderes Públicos, regula derechos y deberes de las personas físicas y jurídicas, tanto públicas como privadas y prevê medidas destinadas a eliminar y corregir em los sectores público y privado, toda forma de discriminación por razón de sexo". ${ }^{15}$

14. HERNÁNDEZ, Teresa García-Berrio. Acciones positivas y cuotas de género ante el derecho. Los mecanismos conteporáneos em la lucha contra la diferencia por razón de sexo. Madrid: Revista de Ciências Jurídicas y Sociales, nº 6, 2007, p. 219 e 220.

15. ESPAÑA, Ley Orgánica 3/2007, de 22 de Marzo, art. 1.2. 
À época da discussão da Lei, apenas o Partido Popular espanhol (PP) absteve-se de votar. Isso porque as pautas de igualdade de gênero e de políticas de afirmação destinadas ao setor empresarial contrariam a ideologia desse partido político. $\mathrm{O}$ chefe do governo, José Luis Rodrigues Zapatero, dedicou a aprovação da Lei à Clara Campoamor, deputada espanhola que, ainda na II República, mais especificamente, no ano de 1931, defendeu o voto feminino ${ }^{16}$.

Essencialmente, a Lei Orgânica no 3 de 2007 (LO 3/2007), ou Ley de Igualdad, instituiu o "princípio de presencia equilibrada" e alterou os parâmetros para a composição da Administração estatal. A lei assim dispôs:

"El Gobierno atenderá al principio de presencia equilibrada de mujeres y hombres en el nombramiento de las personas titulares de los órganos directivos de la Administración General del Estado y de los organismos públicos vinculados o dependientes de ella, considerados en su conjunto, cuya designación le corresponda" ${ }^{\prime 17}$.

A referida Lei determina que as candidaturas de deputados para assentos no Congresso, nos municípios, nos conselhos insulares, no Parlamento Europeu e nas Assembleias Legislativas das Comunidades Autônomas, deverão manter uma proporção de no mínimo $40 \%$ de candidatos para cada sexo. Essa proporção de $40 \%$ para cada sexo deve ser observada, ainda, em relação a cada cinco postos elegíveis. Se houver menos de cinco postos a serem ocupados, a lei dispóe que a proporção entre os sexos deve ser a mais próxima possível do equilíbrio numérico. Ademais, as listas para suplência dos cargos também deve respeitar a proporção ${ }^{18}$.

Em relação às comunidades autônomas, a Lei Orgânica 3/2007 determina uma cláusula de abertura, estipulando que as leis específicas para regulamentação de seus pleitos eleitorais podem determinar medidas que favoreçam, em maior medida, a presença das mulheres nas candidaturas. In verbis:

"En las elecciones de membros de las Asambleis Legislativas de las Comunidades Autónomas, las leyes reguladoras de sus respectivos regímenes electorales podrán estabelecer medidas que favorezcan uma mayor presencia de mujeres em las candidaturas que se presenten a las Elecciones de las citadas Asambleas Legislativas". ${ }^{19}$

Em seu artigo 187, a Lei excluiu os municípios com menos de 3.000 habitantes da obrigatoriedade do cumprimento do art. 44 bis da Ley Orgánica 5/1985, com as modificações de 2007. Para tanto, determina um período de adaptação aos ajustes trazidos pela Ley Orgánica 3/2007: nas eleições municipais anteriores ao ano de 2011, a proporção entre candidatos de diferentes sexos é obrigatória somente aos municípios com população inferior a 5.000 habitantes.

16. OTALORA, Ainhoa Uribe. Las cuotas de género y su aplicación em Espanãł los effectos de la Ley de Igualdad (LO 3/2007) em las Cortes Generales y los Parlamentos Autonómicos. Madrid: Revista de Estudios Políticos, n 160, p. 159-197, abr. 2013, p. 163.

17. ESPANAA, Ley Orgánica 3/2007, de 22 de Marzo, art. 52.

18. ESPANA. Ley Orgánica 5/1985, de 19 de Junio, art. 44 bis (1), (2) e (3).

19. Ibid., art. 44 bis. 
Como a lei estabelece apenas um mínimo para as cotas, cada partido tem a liberdade de manter uma proporção distinta. A maioria dos partidos com representação política, contudo, mantém cotas de $40 \%$ em suas próprias listas. Aos partidos políticos, é ainda concedido um período curto de tempo (48 horas) para ajustar suas listas de candidatos, caso não acatem as disposições normativas, inclusive no que tange às cotas para gêneros. Caso permaneçam inadequadas, as listas são rejeitadas pela Comissão Eleitoral ${ }^{20}$.

\section{Realidade da representatividade feminina na política espanhola: (in)eficácia da Ley de Igualdad}

Para a compreensão da eficácia da Ley de Igualdad, no sistema eleitoral espanhol, é preciso realizar uma divisão na análise dos pleitos eleitorais, ocorridos antes e após a sua aprovação, entre o nível nacional, envolvendo as eleiçóes para as Cortes Generales, e o nível subnacional, envolvendo as eleiçóes para os Parlamentos Autônomos. A análise aqui proposta tem como objeto a proporção de mulheres eleitas nas últimas eleições em relação aos grupos parlamentares, presentes no Senado e na Câmara dos Deputados, bem como a proporção de mulheres entre os candidatos apresentados pelos partidos. Por fim, é analisada a proporção de mulheres eleitas pelas comunidades autônomas espanholas para os parlamentos autônomos.

\section{Eficácia da Ley de Igualdad no Senadoł relação entre senadoras eleitas e grupos parlamentares}

A presença de mulheres no Senado foi incrementada com a imposição de uma composição equilibrada entre homens e mulheres, nas listas partidárias, determinada em pela reforma eleitoral de 2007. Atualmente (Legislatura X, de 2011-2015), há 92 mulheres no Senado. Em 2008, 66 mulheres foram eleitas, contra 54 senadoras da Legislatura anterior, de 2004. A porcentagem de mulheres no Senado era de 25,96\%, em 2004, e de 31,7\%, em 2008. Com as eleições em 20 de novembro de 2011, o percentual chegou a 33,33\% ${ }^{21}$.

Os membros do Senado espanhol podem ser divididos entre grupos parlamentares. Para a atual legislatura (X Legislatura), eleita no ano de 2011, entre o Grupo Parlamentar Popular (GPP), do Partido Popular espanhol e do Partido Aragonés, com 132 membros no Senado, 56 são mulheres (42,42\%). Entre o Grupo Parlamentar Misto (GM), que envolve partidos de abrangência regional, como os partidos Esquerra Republicana, Ciudadanos, Unión del Pueblo Navarro, Solidariedad Vasca, entre outros, dos oito membros eleitos, seis são mulheres (75\%). Entre o Grupo Parlamentar Socialista (GPS), do Partido Obrero Español (PSOE) e suas ramificações, Partido dos Socialistas de Galícia (PSG-PSOE) e o Partido Socialistas de Euskadi-Eskadiko-Eskerra (PSE-EE-PSOE), com 48 membros eleitos, 15 são mulheres (31,25\%). Entre o Grupo Parlamentar Entesa pel progrès de Catalunya (GECP), dos oito membros eleitos, duas são mulheres (25\%). Entre o Grupo Parlamentar Vasco en el Senado (GV), do Partido Nacionalista Vasco, dos quatro membros eleitos, duas são mulheres

20. ESPAÑA. Ley Orgánica 5/1985, de 19 de Junio, art. 47 (2) e (4).

21. SENADO DE ESPAÑA. Senadores en activo. Disponível em: http://www.senado.es/web/composicionorganizacion/senadores/composicionsenado/senadoresenactivo/index.html. Acesso em: 20 set. 2015. 
(50\%). Por fim, para o Grupo Parlamentar Catalán en el Senado de Convergencia i D’Unión (GCIU), dos nove membros eleitos, duas são mulheres $(22,2 \%)^{22}$.

Contudo, é preciso ressaltar que entre os sete senadores membros da Mesa do Senado, apenas duas são mulheres ${ }^{23}$. A Mesa do Senado é composta pelo Presidente, por dois vice-presidentes e quatro secretários. Yolanda Vicente González ocupa atualmente a Segunda Vice-Presidência, eleita pelo Partido Socialista, e Carmen Alborch Bataller, também do Partido Socialista, ocupa o posto de Terceira Secretária ${ }^{24}$.

\subsection{Eficácia da Ley de Igualdad no Senado: relação de candidatas eleitas por partidos políticos}

Quando se observa a presença das mulheres nas listas apresentadas, pelos partidos políticos, para as eleições do Senado, os percentuais de representatividade feminina são menos animadores. Na Legislatura imediatamente posterior à aprovação da Ley de Igualdad (2008-2011), o Grupo Parlamentar Socialista e o Grupo Parlamentar Popular contaram com as maiores proporções de candidatas eleitas ao Senado.

Para a última Legislatura (2011-2015), o partido com a maior porcentagem de mulheres entre os senadores eleitos foi o Convergencia i Unió (38,46\%). Em seguida, o Partido Popular (37,89\%), o Partido Vasco (30\%) e o Entesa pel Progrès de Catalunya (30\%) garantiram, também, percentuais iguais ou acima de 30 . Em termos absolutos, no entanto, é o Partido Popular que conta com o maior número de senadoras, como consequência da sua maior representatividade no Senado.

$\mathrm{Na}$ tabela abaixo, estão organizados os números globais de candidatos a senadores apresentados pelos grupos parlamentares em suas listas e a respectiva porcentagem de mulheres que as compóem:

\footnotetext{
22. SENADO DE ESPAÑA. Senadores en activo. Distribución por Grupos Parlamentarios. Disponível em: http://www.senado.es/web/composicionorganizacion/gruposparlamentarios/composiciongruposparlamentarios/index.html. Acesso em: 21 set. 2015.

23. Id.

24. Id. 
Tabela 1. Quantidade de candidatos por partido político e \% de mulheres

\begin{tabular}{|l|l|l|l|l|l|l|l|}
\hline $\begin{array}{l}\text { LEGISLATURA/ } \\
\text { GRUPO } \\
\text { PARLAMENTAR }\end{array}$ & $\begin{array}{l}\mathbf{2 0 0 4}- \\
\mathbf{2 0 0 8}\end{array}$ & $\begin{array}{l}\mathbf{2 0 0 8}- \\
\mathbf{2 0 1 1}\end{array}$ & $\begin{array}{l}\mathbf{2 0 1 1}- \\
\mathbf{2 0 1 5}\end{array}$ & $\begin{array}{l}\text { LEGISLATURA/ } \\
\text { \% MULHERES }\end{array}$ & $\begin{array}{l}\mathbf{2 0 0 4}- \\
\mathbf{2 0 0 8}\end{array}$ & $\begin{array}{l}\mathbf{2 0 0 8}- \\
\mathbf{2 0 1 1}\end{array}$ & $\begin{array}{l}\mathbf{2 0 1 1} \text { - } \\
\mathbf{2 0 1 5}\end{array}$ \\
\hline TOTAL & $\mathbf{2 5 9}$ & $\mathbf{2 5 5}$ & $\mathbf{2 6 1}$ & TOTAL & $\mathbf{2 5 , 1}$ & $\mathbf{2 8 , 2 4}$ & $\mathbf{3 3 , 3 3}$ \\
\hline Socialista & 96 & 100 & 58 & Socialista & 27,08 & 29 & $\mathbf{2 2 , 4 1}$ \\
\hline Popular & 126 & 120 & 161 & Popular & 24,6 & 29,17 & $\mathbf{3 7 , 8 9}$ \\
\hline CiU & 6 & 7 & 13 & CiU & 16,67 & 28,57 & $\mathbf{3 8 , 4 6}$ \\
\hline Vasco-PNV & 7 & 4 & 10 & Vasco-PNV & 28,57 & 25 & $\mathbf{3 0}$ \\
\hline Coalición Canaria & 4 & & & Coalición Canaria & 0 & & \\
\hline $\begin{array}{l}\text { PSC-ERC-ICV- } \\
\text {-EUA (ECP) }\end{array}$ & 16 & 16 & 10 & $\begin{array}{l}\text { PSC-ERC-ICV- } \\
\text {-EUA (ECP) }\end{array}$ & 25 & 31,25 & $\mathbf{3 0}$ \\
\hline Misto & 4 & 8 & 9 & Misto & 25 & 0 & $\mathbf{2 2 , 2 2}$ \\
\hline
\end{tabular}

Fonte: Instituto de la Mujer y para la Igualdad de oportunidades ${ }^{25}$.

\section{Eficácia da Ley de Igualdad na Câmaraः relação entre deputadas eleitas e grupos parlamentares}

Para a Câmara dos Deputados, na X Legislatura (de 2011 à atualidade), há 148 deputadas mulheres. Igualmente, os membros da Câmara podem ser divididos em grupos parlamentares. Para o Grupo Parlamentar Popular, com 185 membros, 83 são mulheres (44,86\%). Para o Grupo Parlamentar Socialista, com 108 membros, 48 são mulheres (44,4\%). Para o Grupo Parlamentar Misto, com 18 membros, seis são mulheres (33,3\%). Para o Grupo Parlamentar Catalán de Convergència i d'Unió, com 15 membros, cinco são mulheres (33,3\%). Para o Grupo Parlamentar de IU, ICV-EUia, CHA, La Izquierda Plural, com 11 membros, não há mulheres. Para o Grupo Parlamentar de Unión Progreso y Democracia (GUPYD), com cinco membros, duas são mulheres (40\%). Para o Grupo Parlamentar Vasco (GV-EAJ-PNV), com, também, cinco membros, apenas uma é mulher $(20 \%)^{26}$.

A Mesa do Congresso dos Deputados cuida da representação colegiada da Câmara e é composta pelo Presidente do Congresso, quatro vice-presidentes e quatro secretários. Todos os membros são eleitos pela Câmara, no início da Legislatura, devendo ser respeitada a representação dos grupos parlamentares com membros no Congresso. Dos nove membros da Mesa, quatro são mulheres. Duas delas, Celia Villalobos Talero, do Grupo Parlamentar Popular, e Dolors Montserrat Montserrat, também do Grupo Parlamentar Popular, ocupam cargos na vice-presidência da Câmara. María del Carmen Silva Rego e Teresa Cunillera Mestres, ambas do Grupo Parlamentar Socialista, são secretárias da Mesa ${ }^{27}$.

25. IMIO. Mujeres em cifras. Disponível em: http://www.inmujer.gob.es/estadisticas/consulta.do?area=8. Acesso em: 22 set. 2015.

26. CONGRESO DE LOS DIPUTADOS. X Legislatura (2011-Actualidad). Disponível em: http://www. congreso.es/portal/page/portal/Congreso/Congreso/Diputados/DipGrupParl. Acesso em: 22 set. 2015.

27. Id. 


\subsection{Eficácia da Ley de Igualdadः relação entre candidatas à Câmara e partidos políticos}

Em relação à Câmara dos Deputados, menos efetiva foi a Ley de Igualdad para a composição equilibrada entre mulheres e homens. A Legislatura anterior à LO 3/2007 (2004-2008) compreendia um percentual de $36 \%$ de mulheres candidatas às cadeiras da Câmara. Esse índice aumentou apenas 0,29\% para a Legislatura seguinte (2008-2011). Já em 2011, o percentual de mulheres na Câmara retornou para os $36 \%{ }^{28}$. Ou seja, pode-se concluir que a LO 3/2007 não alcançou seus objetivos pela efetiva composição igualitária entre os sexos na composição da Câmara.

A coalização catalã Convergência i Unió, na Legislatura de 2008 a 2011, após a aprovação da Ley de Igualdad, passou a contar com um percentual de $40 \%$ de mulheres entre os seus candidatos eleitos, percentual que caiu, em 2011, para 31,25\%, ainda que a coalizão tenha conseguido eleger seis deputados a mais na Legislatura mais recente ${ }^{29}$.

O Grupo Parlamentar Socialista, em 2008, alcançou o índice de 43\% de candidatas eleitas. Durante o seu período de oposição ao governo, entre 1996 e 2004, o percentual de mulheres eleitas foi de 27,66\%, em 1996, e de 36,8\%, em 2000. Na última Legislatura (20112015), esse percentual alcançou os $46,30 \%{ }^{30}$.

O Partido Popular atingiu 29,87\% de assentos ocupados por mulheres, em 2008; na Legislatura anterior, de 2004 a 2008, o percentual foi de 28,38 e, de 2008 a 2011, foi de 29,87, atingindo os $36,22 \%$, em $2011^{31}$. Os dados relacionando o número de candidatos de cada um dos partidos e a porcentagem de mulheres lançadas a candidaturas estão dispostos na tabela seguir:

28. OTALORA, Ainhoa Uribe. Las cuotas de género y su aplicación em Espanãः los effectos de la Ley de Igualdad (LO 3/2007) em las Cortes Generales y los Parlamentos Autonómicos. Madrid: Revista de Estudios Políticos, nº 160, p. 159-197, abr. 2013, p. 169.

29. OTALORA, Ainhoa Uribe. Las cuotas de género y su aplicación em Espanã: los effectos de la Ley de Igualdad (LO 3/2007) em las Cortes Generales y los Parlamentos Autonómicos. Madrid: Revista de Estudios Políticos, n 160, p. 159-197, abr. 2013, p. 170.

30. Ibid., p. 171.

31. Id. 
Tabela 2. Quantidade de candidatos a deputados/as e \% de mulheres

\begin{tabular}{|l|l|l|l|l|l|l|l|}
\hline $\begin{array}{l}\text { LEGISLATURA/ } \\
\text { TOTAL } \\
\text { DEPUTADAS(OS) }\end{array}$ & $\begin{array}{l}2004- \\
2008\end{array}$ & $\begin{array}{l}2008- \\
2011\end{array}$ & $\begin{array}{l}2011- \\
2015\end{array}$ & $\begin{array}{l}\text { LEGISLATURA/ } \\
\text { MULHERES }\end{array}$ & $\begin{array}{l}2004- \\
2008\end{array}$ & $\begin{array}{l}2008- \\
2011\end{array}$ & $\begin{array}{l}2011- \\
2015\end{array}$ \\
\hline TOTAL & 350 & 350 & 350 & TOTAL & 36 & 36,29 & 36 \\
\hline Socialista & 162 & 169 & 110 & Socialista & 46,3 & 43,2 & 39,09 \\
\hline Popular & 148 & 154 & 185 & Popular & 28,38 & 29,87 & 36,22 \\
\hline IU-ICV & 5 & - & 14 & IU-ICV & 40 & - & 28,57 \\
\hline Catalán-CiU & 10 & 10 & 16 & Catalán-CiU & 10 & 40 & 31,25 \\
\hline Vasco-PNV & 7 & 6 & 5 & Vasco-PNV & 14,29 & 0 & 20 \\
\hline Coalición Canaria & 5 & - & - & Coalición Canaria & 20 & - & - \\
\hline ERC & 8 & - & - & ERC & 12,5 & - & - \\
\hline Misto & 5 & 4 & 15 & Misto & 60 & 75 & 26,67 \\
\hline CDS & - & - & - & CDS & - & - & - \\
\hline ERC-IU-ICBNG & - & 7 & 7 & ERC-IU-ICBNG & - & 14,29 & - \\
\hline $\begin{array}{l}\text { Unión Progreso y } \\
\text { Democracia }\end{array}$ & - & - & 5 & $\begin{array}{l}\text { Unión Progreso y } \\
\text { Democracia }\end{array}$ & - & - & 40 \\
\hline
\end{tabular}

Fonte: Instituto de la Mujer y para la Igualdad de oportunidades ${ }^{32}$.

\section{Eficácia da Ley de Igualdadः relação de mulheres eleitas para as Cortes Generales por Comunidades Autônomas}

No ano de 2008, a representatividade das mulheres apresentou significativo aumento nas seguintes Comunidades Autônomas: Aragón, Asturias, Baleares, Canarias, Cantabria, Galicia, Madrid, La Rioja e Comunidade Valenciana, com percentuais de participação feminina próximos a 40\%. Por outro lado, as Comunidades Autônomas de Castilla León, Extremadura e Castilla La Mancha perderam em representação política feminina. Todavia, em termos globais, o saldo de deputadas ao começo da Legislatura de 2004 a 2008, durante a qual foi aprovada a Ley de Igualdad, e da Legislatura imediatamente posterior (2008-2011) manteve-se similar ao da atual Legislatura (2011-2015) ${ }^{33}$.

A partir da análise dos dados quantitativos, desde 2004 até 2011, pode-se inferir que as medidas de promoção da igualdade alcançaram resultados mais positivos para as comunidades autônomas do que para as Cortes Generales. No ano de 2000, a média de mulheres representantes das Comunidades Autônomas era de 30\%. Já em 2008, esse número aumentou para $41 \%$ e, em 2010 , para $42 \%$.

32. IMIO. Mujeres em cifras. Disponível em: http://www.inmujer.gob.es/estadisticas/consulta.do?area=8. Acesso em: 22 set. 2015.

33. OTALORA, Ainhoa Uribe. Las cuotas de género y su aplicación em Espanã: los effectos de la Ley de Igualdad (LO 3/2007) em las Cortes Generales y los Parlamentos Autonómicos. Madrid: Revista de Estudios Políticos, n 160, p. 159-197, abr. 2013, p. 190. 
Tabela 3. Porcentagem de mulheres entre os membros das Cortes Generales por Comunidade Autônoma

\begin{tabular}{|l|l|l|}
\hline COMUNIDADE AUTÔNOMA & $\begin{array}{l}\text { \% DEPUTADAS } \\
(2004-2008)\end{array}$ & $\begin{array}{l}\% \text { DEPUTADAS } \\
(2008-2011)\end{array}$ \\
\hline Andalucía & 42,62 & 39,34 \\
\hline Aragón & 30,77 & 38,46 \\
\hline Astúrias & 37,5 & 50 \\
\hline Castilla y León & 30,3 & 25 \\
\hline Comunitat Valenciana & 40,63 & 42,42 \\
\hline Canarias & 40 & 46,67 \\
\hline Cantabria & 40 & 60 \\
\hline Cataluña & 38,3 & 36,17 \\
\hline Ceuta & 0 & 0 \\
\hline Castilla La Mancha & 30 & 23,81 \\
\hline Extremadura & 50 & 30 \\
\hline Galicia & 37,5 & 39,13 \\
\hline Baleares & 38 & 50 \\
\hline La Rioja & 25 & 50 \\
\hline Madrid & 25,71 & 40 \\
\hline Melilla & 0 & 0 \\
\hline Navarra & 40 & 40 \\
\hline País Vasco & 31,58 & 16,67 \\
\hline Regíon de Murcia & 33,33 & 30 \\
\hline
\end{tabular}

Fonte: Instituto de la Mujer y para la Igualdad de oportunidades34.

\subsection{Eficácia da Ley de Igualdad relação de mulheres eleitas para os Parlamentos Autônomos por Comunidade Autônoma}

No que tange às eleições para os Parlamentos Autônomos das Comunidades Autônomas, é preciso, primeiramente, realizar a pertinente distinção entre as Comunidades que, antes da aprovação da Lei Orgânica 3/2007, já se preocupavam com medidas de promoção da igualdade entre gêneros. Eram elas: Baleares, Castilla La Mancha, Andalucía e País Vasco.

Em Castilla La Mancha, por exemplo, a obrigatoriedade ao respeito de uma proporção entre candidatas e candidatos, pelos partidos e demais grupos eleitorais, foi adotada em 2002, cinco anos antes da adoção da LO 3/2007. Em Andalucía e no País Vasco, desde 2005, há sistema de cotas inclusas pela alteração da legislação eleitoral. Outras Comunidades Autônomas também tomaram medidas para promoção da igualdade sem, contudo, determinar obrigatoriedade à observância desses mecanismos ${ }^{35}$.

34. IMIO. Mujeres em cifras. Disponível em: http://www.inmujer.gob.es/estadisticas/consulta.do?area=8. Acesso em: 22 set. 2015.

35. OTALORA, Ainhoa Uribe. Las cuotas de género y su aplicación em Espanã: los effectos de la Ley de Igualdad (LO 3/2007) em las Cortes Generales y los Parlamentos Autonómicos. Madrid: Revista de Estudios Políticos: n 160, p. 159-197, abr. 2013, p. 169. 
Em 2004, o percentual de deputadas eleitas, para Castilla La Mancha, já correspondia a 53\%. Na Comunidade Autônoma de Cantabria e na Comunidade Valenciana, 41\% foi o índice de mulheres eleitas. Por fim, Andalucía, com 39\%, e Baleares, com 37\%, foram as Comunidades que quase cumpriam a disposição que traria Lei Orgânica 3/2007, três anos mais tarde ${ }^{36}$.

Em 2008, logo após a aprovação da LO 3/2007, apenas Castilla La Mancha superou o equilíbrio entre os sexos, com mais de $53 \%$ de deputadas, enquanto, nas Ilhas Baleares, o percentual foi próximo de $50 \%$, com $49 \%$ de deputadas. Em seguidas, as Comunidades com os maiores percentuais deputadas foram: Comunidade Valenciana, Andalucía e País Vasco, cada uma com percentual próximo a $45 \%^{37}$.

Para as eleiçôes de 2011, os resultados foram similares aos da Legislatura Anterior (de 2008). As Comunidades que apresentaram menos mulheres eleitas do que na Legislatura anterior foram: Aragón, Baleares, Canarias, Cantabria, Castilla La Mancha, Navarra, Comunidade Valenciana e País Vasco. Em Castilla León, a porcentagem de mulheres eleitas em relação aos homens foi de 43 para 66\%. Andalucía, Astúrias, Baleares, Cantabria, Castilla León, Cataluña, Madrid, Comunidade Valenciana e País Vasco mantiveram percentual acima da cota exigida pela LO 3/2007, com mais que $40 \%$ de mulheres ${ }^{38}$.

Dessa forma, pode-se concluir que, entre as Comunidades Autônomas, a composição equilibrada, aludida pela Ley de Igualdad, foi alcançada. Todavia, antes de estabelecer a relação de causa-efeito entre a Lei e o aumento do percentual de mulheres representantes, é preciso observar que, em algumas Comunidades, a proporção equilibrada entre os sexos corresponde, em maior medida, à adoção de alteraçôes legislativas de abrangência local, e não à Lei Orgânica $3 / 2007^{39}$.

36. Ibid., p. 176.

37. Ibid., p. 170 .

38. OTALORA, Ainhoa Uribe. Las cuotas de género y su aplicación em Espanã: los effectos de la Ley de Igualdad (LO 3/2007) em las Cortes Generales y los Parlamentos Autonómicos. Madrid: Revista de Estudios Políticos: n 160, p. 159-197, abr. 2013, p. 177.

39. Ibid., p. 176. 
Tabela 4. Número de assentos e \% de mulheres nos Parlamentos Autônomos

\begin{tabular}{|l|l|l|l|l|l|l|l|}
\hline $\begin{array}{l}\text { COMUNIDADE } \\
\text { AUTÔNOMA }\end{array}$ & 2004 & 2008 & 2011 & \% Mulheres & 2004 & 2008 & 2011 \\
\hline TOTAL & $\mathbf{1 . 2 6 8}$ & $\mathbf{1 . 2 6 8}$ & $\mathbf{1 . 2 6 8}$ & TOTAL & 35,97 & $\mathbf{4 1 , 6 7}$ & $\mathbf{4 3 , 1 4}$ \\
\hline Andalucía & 109 & 109 & 109 & Andalucía & 39,45 & 45,87 & 45,87 \\
\hline Aragón & 67 & 67 & 67 & Aragón & 31,34 & 35,82 & 32,84 \\
\hline Astúrias & 45 & 45 & 45 & Astúrias & 31,11 & 33,33 & 42,22 \\
\hline Baleares & 59 & 59 & 59 & Baleares & 37,5 & 49,15 & 45,76 \\
\hline Canarias & 60 & 60 & 60 & Canarias & 35 & 40 & 36,67 \\
\hline Cantabria & 39 & 42 & 39 & Cantabria & 41,03 & 40,48 & 43,59 \\
\hline Castilla León & 75 & 83 & 84 & Castilla León & 36 & 43,37 & 66,67 \\
\hline Castilla La Mancha & 47 & 47 & 49 & Castilla La Mancha & 53,19 & 53,19 & 46,94 \\
\hline Cataluña & 135 & 135 & 135 & Cataluña & 29,63 & 36,30 & 41,5 \\
\hline Ceuta & 24 & 25 & 25 & Ceuta & 33,33 & 40 & 40 \\
\hline Extremadura & 65 & 65 & 65 & Extremadura & 36,92 & 40 & 40 \\
\hline Galicia & 75 & 75 & 75 & Galicia & 33,33 & 33,33 & 40 \\
\hline Madrid & 111 & 120 & 129 & Madrid & 37,84 & 42,5 & 44,19 \\
\hline Murcia & 45 & 46 & 45 & Murcia & 31,11 & 39,13 & 40 \\
\hline Navarra & 50 & 50 & 50 & Navarra & 32 & 38 & 34 \\
\hline La Rioja & 33 & 33 & 33 & La Rioja & 39,39 & 39,39 & 39,39 \\
\hline C. Valenciana & 89 & 99 & 99 & C. Valenciana & 41,57 & 45,45 & 40,40 \\
\hline País Vasco & 75 & 75 & 75 & País Vasco & 34,67 & 52 & 45,33 \\
\hline Melilla & 26 & 25 & 25 & Melilla & 30,77 & 40 & 40 \\
\hline
\end{tabular}

Fonte: Instituto de la Mujer y para la Igualdad de oportunidades ${ }^{40}$.

\section{Eficácia da Ley de Igualdadः relação de mulheres nos partidos políticos}

Ainda que a presença de mulheres nos cargos parlamentares seja globalmente razoável (39,09\%), esse percentual foi maior na Legislatura 2004-2008 do que na Legislatura 20082011. A partir da análise específica dos partidos, percebe-se o interesse, intensificado pela aprovação da Ley de Igualdad, pela ampliação da participação feminina entre seus filiados, havendo, entretanto, exceçóes. O Partido Centro Democrático e Social (CDS), por exemplo, jamais elegeu deputadas, apesar de ocupar 12 assentos nas Cortes Generales.

Entre os partidos de matiz nacionalista, como o Partido Nacionalista Vasco (PNV) e o Convergéncia i Unió (CiU), a incorporação de mulheres é menos significativa e, muitas vezes, incongruente. O PNV aprovou, em seu período de governo, no ano de 2005, a Ley Vasca de Igualdad, estabelecendo a cota de 50\% para as listas eleitorais locais. No entanto, em sua própria apresentação de candidaturas, para a Câmara dos Deputados, nenhuma mulher

40. IMIO. Mujeres em cifras. Disponível em: http://www.inmujer.gob.es/estadisticas/consulta.do?area=8. Acesso em: 22 set. 2015. 
encabeçou as suas listas eleitorais. O PNV também não elegeu deputadas durante quatro legislaturas (1986-1989, 1989-1993, 1993-1996, 2008-2011) ${ }^{41}$.

Assim, Otalora ${ }^{42}$ conclui que o Partido assumiu a medida de promoção dos direitos femininos, mais pela pressão midiática e política do que pela convicção de suas lideranças, em prol dos direitos femininos. O CiU, por sua vez, após a aprovação da Lei Orgânica 3/2007, passou de 0 a $40 \%$ de participação feminina em suas listas, alcançando a proporção de $31,25 \%$ mulheres eleitas, em relação aos homens eleitos, para a Legislatura atual (2011-2015) ${ }^{43}$.

De outro lado, o Partido Socialista e o Partido Popular são aqueles que mais demonstram a preocupação com a incorporação das mulheres na política, por motivos distintos. Enquanto o Partido Socialista conta com o maior número de mulheres na Câmara dos Deputados, o Partido Popular conta com o maior número de mulheres no Senado. De forma genérica, entre esses partidos (PP e PSOE), houve gradual incorporação de mulheres às listas eleitorais, ocorrida previamente à Ley de Igualdad.

Enquanto para os populares houve saldo positivo nas duas legislaturas posteriores à Lei, com aumento de 1,49\%, em 2008, e de 6,25\%, em 2011; para os socialistas, houve perdas sucessivas em representatividade, com a redução de 3,1\%, em 2008, e de 4,11\%, em 2011. O Grupo Socialista incorporou mulheres entre seus filiados desde a década de noventa (46,30\%). As pressões realizadas pelas militantes socialistas levaram a uma modificação do Estatuto Partidário do PSOE, em 1997, que passou a estabelecer, no seu art. 9.1, o que segue:

“(...) el partido se pronuncia por la democracia paritaria entre hombres y mujeres y, em consecuencia, adopta el sistema de representación em virtude del cual ningún sexo tendrá menos del $40 \%$ ni más del $60 \%$ de representación em cualquier órgano de dirección, control o ejecutivo del partido" ${ }^{\prime 4}$.

O PP foi o partido que mais recursos de inconstitucionalidade propôs contra as Leis que pautam cotas para promoção da igualdade material entre os gêneros. Por outro lado, é o partido com mais filiadas eleitas, ocupando as presidências dos Conselhos Autônomos. Para 2011, os populares aumentaram a proporção de mulheres na Câmara, de 36,22\%. Antes da aprovação da LO 3/2007, na Legislatura de 2000 a 2004, o PP tinha 30\% de mulheres na Câmara dos Deputados ${ }^{45}$.

41. OTALORA, Ainhoa Uribe. Las cuotas de género y su aplicación em Espanã: los effectos de la Ley de Igualdad (LO 3/2007) em las Cortes Generales y los Parlamentos Autonómicos. Madrid: Revista de Estudios Políticos, nº 160, p. 159-197, abr. 2013, p. 171.

42 Ibid., p. 163.

43 Ibid., p. 179.

$44 \quad$ Ibid., p. 182.

45. OTALORA, Ainhoa Uribe. Las cuotas de género y su aplicación em Espanã: los effectos de la Ley de Igualdad (LO 3/2007) em las Cortes Generales y los Parlamentos Autonómicos. Madrid: Revista de Estudios Políticos, n 160, p. 159-197, abr. 2013, p. 171. 


\section{CONCLUSÓES}

A Ley Orgánica 3/2007 alterou o artigo 44 bis da Ley Orgánica 5/1985, sobre o Regime Eleitoral Geral espanhol. Pela alteração legislativa, foram instituídas duas formas de adoção de cotas eleitorais na Espanha: a adoção legislativa, como a realizada pela Ley de Igualdad, em 2007, e como as realizadas no âmbito regional de diversas Comunidades Autônomas; e a adoção partidária, visto que, cada partido tem liberdade para criar cotas internas, através de seus regimentos.

Mesmo com a modificação do art. 44 bis da LOREG, a ocupação dos postos preferenciais nas listas partidárias, pelas mulheres, ainda é deficitária. Essa presença deficitária é também observada entre os cargos mais altos do Executivo. As presidências das Comunidades Autônomas são timidamente ocupadas pelas mulheres, num total de 5,26\% ${ }^{46}$. Nas eleições de 2011, somaram-se à Esperanza Aguirre, presidente da Comunidade de Madri, Luisa Fernanda Rudi, presidente de Aragón, María Dolores de Cospedal, presidente de Castilla La Mancha, e Yolanda Barcina, presidente da Comunidade Navarra. Porém, em relação à Presidência do governo, à Presidência das Cortes Generales e aos Ministérios, a presença das mulheres é ainda esporádica. O que se observa que os espaços "menos interessantes", do ponto de vista político, como para o Parlamento Europeu ou, até mesmo, para o Senado, compreendem as listas em que há maior titularidade de mulheres ${ }^{47}$.

Diante de todos os dados expostos, pode-se concluir que a LO 3/2007 melhorou o"empowerment" das mulheres, embora não tenha sido suficiente para alcançá-lo em todas as instâncias de poder. Para o Senado e para os Parlamentos Autônomos, houve aumento na proporção de mulheres eleitas. Contudo, para a Câmara dos Deputados, essa afirmação não se mantém. Em relação às Comunidades Autônomas, aquelas que adotaram as cotas em suas legislaçóes eleitorais antes da LO 3/2007 alcançaram maior representatividade feminina. Desse modo, não se pode afirmar que o "empoderamento" das candidatas decorreu exclusivamente da $\mathrm{LO} 3 / 2007$.

Para Otalora ${ }^{48}$, a diferença de eficácia da LO 3/2007 entre as Casas Legislativas, dáse pela distinção entre os sistemas majoritário e proporcional. Para as listas do Senado, três candidatos são apresentados, isto é, por meio de listas ímpares. Assim, na maioria das circunscriçôes, há um candidato de um sexo e dois de outro, sendo impossível a composição equilibrada. O voto preferencial do eleitor, de escolha dos candidatos que deseja para o Senado, em consonância ao desenho das listas, acaba por determinar a paridade observada entre senadores eleitos.

Entre as Comunidades Autônomas, as eleições os Parlamentos Autônomos compreendem uma distribuição proporcional. Aos grupos parlamentares de maior representação política são destinados mais assentos. Dessa forma, há grupos parlamentares que podem apresentar somente um candidato, impedindo a paridade.

\footnotetext{
46. Ibid., p. 191.

47. Id.

48. OTALORA, Ainhoa Uribe. Las cuotas de género y su aplicación em Espanã: los effectos de la Ley de Igualdad (LO 3/2007) em las Cortes Generales y los Parlamentos Autonómicos. Madrid: Revista de Estudios Políticos, n 160, p. 159-197, abr. 2013, p. 189.
} 
Nesse caso, não se pode defender que o eleitor realize um voto de gênero, primando pelas mulheres candidatas em detrimento dos homens. Também não parece razoável impor aos partidos que ofereçam listas fechadas, impossíveis de alteração de ordem de preferência dos candidatos, cabendo, ao eleitor, a mera adesão pelo voto. Otalora, assim, resume os fatores que afetam a ideal eficácia das cotas eleitorais:

"De um lado, la voluntad del partido de incorporar mujeres entre los primeiros puestos de las listas. De outro lado, la existência de um cambio sociológico que haga que la politica interesse más a las mujeres como salida professional; $y$, por ultimo, en el diseño de la cuota electoral, esto es, em la imposición de listas cremallera". ${ }^{49}$

Para muitos autore ${ }^{50}$, o sistema proporcional é mais igualitário do que o sistema majoritário. No entanto, inexiste consenso doutrinário ${ }^{51}$. Para outros autore ${ }^{52}$, entretanto, quanto maior o tamanho da circunscrição eleitoral, mais equilibrados são os resultados dos pleitos, em relação ao gênero. Uma vez que as circunscrições eleitorais espanholas são as províncias, há pequeno espaço para a garantia de pleitos igualitários. Para a sua alteração, seria necessária a modificação da Constituição.

Outra questão apontada pelos especialistas refere-se à diferença entre listas abertas e listas fechadas. Em teoria, as listas abertas não ofereceriam garantia o respeito do princípio igualitário ${ }^{53}$. Dessa afirmação, seria necessário concluir que, na Câmara de Deputados, a proporção de mulheres deveria ser maior do que no Senado, já que, na primeira, há listas fechadas, combinadas com um sistema proporcional, enquanto no Senado há listas abertas, combinadas com um sistema majoritário. Ainda que, em termos quantitativos, haja mais mulheres na Câmara dos Deputados do que no Senado, a eficácia da LO 3/2007 é mais notada na última Casa Legislativa.

A política de cotas eleitorais, mundialmente, é pejorativamente chamada de medida de "discriminação inversa", porque, segundo alguns autores, provocaria um dano coletivo aos não beneficiados por essa medida. No caso da política positiva adotada pela Ley de Igualdad, esse dano coletivo seria causado aos homen ${ }^{54}$. Sobre a justiça e a constitucionalidade das cotas, o Tribunal Constitucional espanhol, na STC 12/2008, assim se manifestou:

49. Ibid., p. 166.

50. MATLAND, Richard. DWIGHT, Deborah. Disctrict magnitude's effect on female representation in State legislatures. Legislative Studies Quarterly: n 17, 1992, p. 469-492.

51. OTALORA, Ainhoa Uribe. Las cuotas de género y su aplicación em Espanã: los effectos de la Ley de Igualdad (LO 3/2007) em las Cortes Generales y los Parlamentos Autonómicos. Madrid: Revista de Estudios Políticos, n 160, p. 159-197, abr. 2013, p. 165.

52.WELCH, Susan. STUDLAR, Donley. Multi-member districts and the representation of women: evidence from Britain and the United States. The Journal of Politics $¥ n^{\circ} 52,1990$, p. 391-412.

53. DAHLERUP, Drude. Women, quotas and politics. New York: Routledge, 2006.

54. MARTÍNEZ ALARCÓN, Maria Luz. Cuota electoral de mujeres y derecho constitucional. Madrid: Congreso de los Diputados, 2006, p. 117. 
“(...) el principio de composición equilibrada de las candidaturas electorales se asienta sobre um critério natural y universal, como es el sexo (...). Los candidatos defienden opciones políticas diversas ante el conjunto del electoral $y$, caso de recibir respaldo de éste, lo representarán también em su conjunto y no sólo a los electores de sum ismo sexo." ${ }^{55}$

É preciso, contudo, observar a melhora apresentada, no que tange ao aumento da representatividade das mulheres na política espanhola, de modo global, sem ignorar as problemáticas sociais seculares, que ainda padecem de solução, como a desigualdade salarial, a precariedade do trabalho feminino e a ausência de mulheres que ocupem os principais centros de poder e de tomada de decisões ${ }^{56}$.

Para Pitkin ${ }^{57}$, é importante notar que a igualdade efetiva entre mulheres e homens apresenta duas dimensões de interesse. A primeira é quantitativa e diz respeito à existência de um mesmo número de mulheres e de homens ocupando postos de trabalho em entidades públicas e privadas. A segunda é qualitativa e diz respeito à representação substancial, no processo e nos resultados das decisóes, incluindo o âmbito do Poder Público, como reflexo dos interesses e das necessidades das mulheres.

A igualdade não é questão apenas de número, mas de poder, de controle da tomada das decisões. Assim, é importante analisar o poder que possuem as mulheres incorporadas aos quadros dos partidos e a relevância que detêm nos cargos públicos que ocupam, seja no Legislativo, no Executivo ou no Judiciário ${ }^{58}$.

Assim, ainda que haja melhora na posição da mulher na política espanhola, após a adoção da Ley de Igualdad (e também das Leis aprovadas nas Comunidades Autônomas), a sua eficácia não é plenamente satisfatória. A garantia da igualdade, conforme aponta Otalaro ${ }^{59}$, não pode nem deve impor-se, mas deve resultar de um esforço conjunto da sociedade. Isso compreende, essencialmente, a educação, em igualdade de condições, para superação de preconceitos seculares, que envolvem estereótipos que atribuem, às mulheres, uma vida laboral privativa em prol de uma vida familiar expansiva e, aos homens, profissóes masculinizadas, como tem sido a política.

55. Ibid., p. 133-134.

56. ORTIZ LALLANA, Maraia del Carmen. Igualdad de derechos y oportundiades entre el hombre y la mujer en la Unión Europea. Revista del Ministerio de Trabajo e Inmigraciónः n 47, 2003, p. 99-109.

57. PITKIN, Hanna Fenichel. The concept of representation. Berkeley: University of California, 1967.

58. MARTÍNEZ ALARCÓN, Maria Luz. Cuota electoral de mujeres y derecho constitucional. Madrid: Congreso de los Diputados, 2006, p. 117.

59. OTALORA, Ainhoa Uribe. Las cuotas de género y su aplicación em Espanã: los effectos de la Ley de Igualdad (LO 3/2007) em las Cortes Generales y los Parlamentos Autonómicos. Madrid: Revista de Estudios Políticos, no 160, p. 159-197, abr. 2013, p. 191. 


\section{Referências}

BANCO MUNDIAL. Data by country: Spain. Disponível em: <http://data.worldbank. org/country/spain >. Acesso em: 18 mar. 2015.

AGENCIA ESTATAL BOLETÍN OFICIAL DEL ESTADO (BOE). La Constitución Española. Disponível em: <https://www.boe.es/legislacion/constitucion.php/>. Acesso em: 10 set. 2015 .

CASTRILLÓN, Gonzalo Anes y Álvarez. Veinticinco años de la Constitución Española. Real Academia de la Historia: Madrid, 2006, p. 54.

CONGRESO DE LOS DIPUTADOS. X Legislatura (2011-Actualidad). Disponível em: <http://www.congreso.es/portal/page/portal/Congreso/Congreso/Diputados/DipGrupParl>. Acesso em: 22 set. 2015.

DAHLERUP, Drude. Women, quotas and politics. New York: Routledge, 2006.ESPANA. Constitución Española. ESPAÑA. Ley Organica 5/1985, de 19 de Junio. ESPAÑA, Ley Orgánica 3/2007, de 22 de Marzo.

GALLEGO MÉNDEZ, María Teresa. Women's Political Engagement in Spain. Londres: Yale University Press, 1994, p. 660-673.

HERNÁNDEZ, Teresa García-Berrio. Acciones positivas y cuotas de género ante el derecho. Los mecanismos conteporáneos em la lucha contra la diferencia por razón de sexo. Madrid: Revista de Ciências Jurídicas y Sociales, nº 6, 2007, p. 219 e 220.

IMIO: Instituto de la Mujer y para la Igualdad de oportunidades. Mujeres em cifras. Disponível em: <http://www.inmujer.gob.es/estadisticas/consulta.do?area=8>. Acesso em: 22 set. 2015.

INE. Instituto Nacional de Estadística. Disponível em: <http://www.ine.es/inebmenu/ mnu_cifraspob.htm/ >.Acesso em: 18 mar. 2015.

MARTÍNEZ ALARCÓN, Maria Luz. Cuota electoral de mujeres y derecho constitucional. Madrid: Congreso de los Diputados, 2006, p. 133-134.

MATLAND, Richard. DWIGHT, Deborah. Disctrict magnitude's effect on female representation in State legislatures. Legislative Studies Quarterly: no 17, 1992, p. 469-492.

ORTIZ LALLANA, Maraia del Carmen. Igualdad de derechos y oportundiades entre el hombre y la mujer en la Unión Europea. Revista del Ministerio de Trabajo e Inmigración: $n^{\circ} 47,2003$, p. 99-109. 
OTALORA, Ainhoa Uribe. Las cuotas de género y su aplicación em Espanã: los effectos de la Ley de Igualdad (LO 3/2007) em las Cortes Generales y los Parlamentos Autonómicos. Madrid: Revista de Estudios Políticos, no 160, p. 159-197, abr. 2013, p. 163.

PITKIN, Hanna Fenichel. The concept of representation. Berkeley: Universidad de California, 1967.

SENADO DE ESPAÑA. Funciones del Senado. Disponível em: <http://www.senado.es/ web/conocersenado/temasclave/funcionessenado/index.html>. Acesso em: 15 ago. 2015.

VALCÁRCEL, Amelia. El debate sobre el voto femenino en la Constitución de 1931. Madrid: Congreso de los Diputados, 2002.

WELCH, Susan. STUDLAR, Donley. Multi-member districts and the representation of women: evidence from Britain and the United States. The Journal of Politics, $\mathrm{n}^{\circ}$ 52, 1990, p. 391-412.

WORLD FORUM ECONOMICS. Global Gender Gap Report. Disponível em: <http:// reports.weforum.org/global-gender-gap-report-2014/economies/\#economy=ESP $>$. Acesso $\mathrm{em}: 20$ set. 2015 . 
Recebido em: $10 / 11 / 2015$

Aceito em: 02/12/2015

\section{Como citar}

TAVARNARO, Claudia Pilatti. O sistema de cotas eleitorais na Espanha: uma análise da Ley de Igualdad (LO3/2007). Ballot. Rio de Janeiro: UERJ. Volume 1 Número 2 Setembro/Dezembro 2015. pp. 140-161. Disponível em: [http://www.e-publicacoes.uerj.br/index.php/ballot]

\section{(c) $(90$}

A Revista Ballot está licenciada sob uma licença Creative Commons Atribuição - Não Comercial - Compartilha Igual 3.0 Não Adaptada. 